Góes-Souza K.R.; Costa, V.C. A análise ambiental integrada norteando o planejamento Ecoturístico: uma proposta de estudo de caso em Duas Barras (RJ). Revista Brasileira de Ecoturismo,

\title{
A análise ambiental integrada norteando o planejamento Ecoturístico: uma proposta de estudo de caso em Duas Barras (RJ)
}

\author{
The environmental analysis integrated at orienting Ecoturistic planning: a \\ proposal for a case study in Duas Barras (RJ), Brazil
}

\section{Kátia Regina Góes-Souza, Vivian Castilho da Costa}

\section{RESUMO}

O ecoturismo é uma das modalidades de turismo da natureza que mais tem crescido, sendo visto como alternativa econômica para municípios de médio e pequeno porte que possuem Unidades de Conservação em seus territórios ou áreas com remanescentes florestais ou ainda áreas de interesse geológico, geomorfológico, concentração hídrica que possam atrair o turista. A preocupação quanto ao sustento da atividade turística desta categoria ocorre, quando o ambiente natural em exploração não possui instrumento legal como planejamento ambiental auxiliando na gestão e na tomada de decisão. Neste contexto, este artigo versa sobre a importância de analisar geoindicadores de sustentabilidade ambiental, que auxiliem no suporte a tomada de decisão no que concerne ao desenvolvimento de atividades turísticas no município de Duas Barras, RJ. Como objetivos específicos podem ser destacados: desenvolver geoindicadores de sustentabilidade ambiental e diagnosticar as potencialidades e fragilidades ambientais.

PALAVRAS-CHAVE: Ecoturismo; Planejamento; Geoprocessamento; Geoindicadores.

\section{ABSTRACT}

Ecotourism is a type of tourism in the nature that is growing up a lot and it have been an economic alternative for medium and small municipalities with Conservation Unities in the territories, forest remnants, geological and geomorphological interest areas and water resources that catch the tourist. We are concerned about the sustainability of this type of tourism when the natural tourist area doesn't has environmental plans to help in the management and decisions. In this context, this paper discusses about the importance to analyze the environmental geoindicators of environmental sustainably which support decisions about the development of tourist activities in Duas Barras city, localized in Rio de Janeiro. The specific aims were highlighted: to develop geoindicators of environmental sustainability and to diagnose the potentialities and fragilities of the environmental area.

KEYWORDS: Ecotourism, Planification, Geoprocessing, Geoindicators. 
A análise ambiental integrada norteando o planejamento Ecoturístico: uma proposta de estudo de caso em Duas Barras (RJ)

\section{Introdução}

A atividade turística é a atividade do setor terciário que lida com o imaginário, criatividade e com o sonho das pessoas gerando expectativas entorno das viagens. Além da escolha do destino, esta promissora atividade, agrega também serviços de hospedagens, alimentação, passeios, compras, lazer, capacitação de profissionais, arquitetura e decoração, cultura, etc.

Segundo o IBGE (2008), diante dessa engrenagem de serviços que visam satisfazer o turista, o turismo é considerado um fenômeno social e econômico mais promissor nos últimos anos, já podendo ser considerada uma das atividades econômicas que mais cresce no país. Por esse motivo, o turismo tradicional, ou seja, aquele que se descreve nas características dos visitantes, nas condições que levaram a cabo suas viagens e estadas, o motivo de sua visita, etc., têm sido complementadas por uma perspectiva de caráter econômico.

Em um mundo globalizado em que se tem um fluxo de informações quase que em tempo real sobre qualquer parte do mundo, se crê que quase já não exista local anônimo sobre a superfície do planeta. A evolução da tecnologia da informação, associada ao ambiente inquietante das grandes cidades, de uma rotina forjada sobre muita pressão, fez emergir uma necessidade, quase que vital, da população citadina em habitar outros espaços com baixa densidade demográfica, maior contato com a natureza, praticar caminhadas, fazer trilhas, esportes radicais ou simplesmente descansar. É neste contexto de preocupações com as questões ambientais que surge o turismo sustentável que alicerçado sobre as bases do desenvolvimento sustentável preocupase em se desenvolver atendendo as dimensões: social, econômica, ambiental e político-institucional. Para Delamaro (2002) o turismo sustentável visa satisfazer as necessidades do presente sem comprometer as necessidades das gerações futuras.

O ecoturismo é uma das modalidades de turismo da natureza que mais tem crescido, sendo visto como alternativa econômica para municípios de médio e pequeno porte que possuem Unidades de Conservação em seus territórios ou áreas com remanescentes florestais ou ainda áreas de interesse geológico, geomorfológico, concentração hídrica que possam atrair o turista. A preocupação quanto ao sustento da atividade turística desta categoria ocorre, quando o ambiente natural em exploração não possui instrumento legal como planejamento ambiental auxiliando na gestão e na tomada de decisão.

Sendo assim, para delinear o instrumento legal, faz-se necessário o estudo prévio da área, através do diagnóstico, detectando as potencialidades e fragilidades ambientais. Para tal, o geoprocessamento têm papel ímpar não somente como ferramenta de espacialização da informação, mas principalmente como coadjuvante no desenvolvimento de modelos e indicadores que facilitam enormemente equacionar a visão integrada do meio ambiente.

Neste contexto são objetivos deste estudo analisar geoindicadores de sustentabilidade ambiental, que auxiliem no suporte a decisão no que concerne ao desenvolvi- 
mento de atividades turísticas no município de Duas Barras, RJ. Como objetivos específicos podem ser destacados: desenvolver geoindicadores de sustentabilidade ambiental e diagnosticar as potencialidades e fragilidades ambientais.

\section{Desenvolvimento sustentável}

O conceito de desenvolvimento sustentável se consolidou por volta dos anos 80 , durante a conferência da ONU, em 1987, que deu origem ao Relatório Nosso Futuro Comum $^{1}$. Contudo, as preocupações com o meio ambiente vinham sendo discutidas desde os anos 70, com o Clube de Roma ${ }^{2}$ e o Relatório os limites do crescimento, cuja preocupação era identificar os maiores impactos ambientais globais.

De fato os países desenvolvidos, em sua maioria líderes econômicos do hemisfério norte, começaram a se preocupar com os sinais de desequilíbrios ambientais, nos âmbitos: local, regional e mundial, distribuídos em diversos pontos do planeta, sinalizando a gestão inadequada dos recursos naturais. O meio Ambiente ao longo dos anos vem sutilmente dando sinais de desequilíbrio em resposta a séculos contínuos de gestão inadequada e exploração acelerada de seus recursos naturais em detrimento de um modelo desenvolvimentista no qual não é respeitado o tempo necessário para recomposição dos recursos naturais, levando-os ao esgotamento.

Neste contexto mundial de preocupações com o futuro do planeta, surgiram as conferências de Estocolmo (1972), Vancouver (1976) e Rio-92, onde o desafio era repensar uma forma de continuar se desenvolvendo economicamente e tecnologicamente e ao mesmo tempo saber respeitar o tempo de resiliência, através da conservação do meio ambiente, fazendo o uso do recurso natural de forma sustentável, tentando criar assim uma relação harmoniosa entre homem e a natureza, conciliando desenvolvimento econômico, conservação do meio ambiente e bem estar social.

Segundo Christofolitti (1999), o termo desenvolvimento sustentável, começou a ser utilizado no início da década de 70, em conversão sobre desenvolvimento e meio ambiente realizada em Cocoyaca, mas foi em 1987 que o conceito foi expresso como a base da expressão integrativa para a política econômica.

Segundo a CMMAD (Comissão Mundial sobre Meio Ambiente e Desenvolvimento), "Desenvolvimento Sustentável é aquele que atende às necessidades do presente sem comprometer a possibilidade de que as gerações futuras satisfaçam as suas próprias necessidades". A idéia deriva do conceito de ecodesenvolvimento proposto por Maurice Strong e Ignacy Sachs, durante a primeira conferência sobre Meio Ambiente e Desenvolvimento (Estocolmo, 1972).

Em 1987, considerado um dos momentos mais importantes para este novo modelo de desenvolvimento, a Primeira-Ministra da Noruega, Gro Harlem Brundtland, Presidente da Comissão, adotou o conceito de Desenvolvimento Sustentável em seu relatório Our Common Future (Nosso futuro comum), também conhecido como Relatório Brundtland. 
A análise ambiental integrada norteando o planejamento Ecoturístico: uma proposta de estudo de caso em Duas Barras (RJ)

Em 1992, durante a Conferência das Nações Unidas sobre Meio Ambiente e Desenvolvimento, a Cúpula da Terra de 1992 - Eco-92, no Rio de Janeiro, o conceito foi definitivamente incorporado como um princípio. O Desenvolvimento Sustentável busca o equilíbrio entre proteção ambiental e desenvolvimento econômico e serviu como base para a formulação da Agenda $21^{3}$, com a qual mais de 170 países se comprometeram, por ocasião da Conferência. Trata-se de um abrangente conjunto de metas para a criação de um mundo, enfim, equilibrado.

A Declaração da Cúpula Mundial sobre Desenvolvimento Sustentável de Joanesburgo em 2002, afirma a necessidade de "fazer avançar e fortalecer os pilares interdependentes e mutuamente apoiados do desenvolvimento sustentável - desenvolvimento econômico, desenvolvimento social e proteção ambiental - nos âmbitos local, nacional, regional e global" (MMA, 2007).

Deste modo, esse paradigma reconhece a complexidade e o interrelacionamento de questões críticas como pobreza, desperdício, degradação ambiental, decadência urbana, crescimento populacional, igualdade de gêneros, saúde, conflito e violência aos direitos humanos.

Os quatro principais elementos do Desenvolvimento Sustentável são: sociedade, ambiente, economia e cultura.

Sociedade: uma compreensão das instituições sociais e seu papel na transformação e no desenvolvimento.

Ambiente: a conscientização da fragilidade do ambiente físico e os efeitos sobre a atividade humana e as decisões.

Economia: sensibilidade aos limites e ao potencial do crescimento econômico e seu impacto na sociedade e no ambiente, com o comprometimento de reavaliar os níveis de consumo pessoais e da sociedade.

Cultura: é geralmente omitido como parte do DS (Desenvolvimento Sustentável). Entretanto, valores, diversidade, conhecimento, línguas e visões de mundo associado à cultura formam um dos pilares do DS e uma das bases da EDS (Educação para o Desenvolvimento Sustentável - MMA, 2007).

Sobre o conceito de Desenvolvimento Sustentável, podem ainda ser citadas outras fontes:

"O progresso social que reconhece as necessidades de todos, a proteção efetiva do meio ambiente, o uso prudente dos recursos naturais e a manutenção de um crescimento econômico e do emprego elevado e estável" (DEPARTAMENTO DO MEIO AMBIENTE, DE TRANSPORTE E DAS REGIÕES DO REINO UNIDO, 1999).

"Desenvolvimento econômico e social que provê as necessidades da geração atual sem solapar a capacidade das futuras gerações de prover suas próprias necessidades"(ESTRATÉGIAS NACIONAIS PARA O DESENVOLVIMENTO SUSTENTÁVEL, 2000). 
Oliveira (2000), define Desenvolvimento Sustentável como uma forma de se desenvolver satisfazendo as necessidades do presente sem comprometer as necessidades das gerações futuras. Para isso, o desenvolvimento sustentável deve abranger 6 dimensões (DELAMARO, 2002): social (promoção do bem-estar social), econômica (crescimento econômico planejado), cultural (conscientização e valorização cultural), ambiental (preservação e valorização do patrimônio natural), espacial (ocupação do solo) e político-institucional (coersão e gestão participativa).

Mesmo após mais de 20 anos de existência, este tema ainda é muito polêmico e controverso. O paradoxo reside na dificuldade de conceber desenvolvimento e sustentabilidade em um mesmo conceito, quando o referencial de desenvolvimento está ainda muito arraigado a crescimento econômico e este, por sua vez, referenciado aos padrões adotados pela liderança econômica mundial (OLIVEIRA, op. cit).

Segundo Goes (2007), outro ponto frágil trazido por essa discussão é o fato dessa preocupação com o futuro do planeta ter se manifestado justamente quando as reservas dos hemisférios norte encontram-se em vias de esgotamento e os países emergentes do hemisfério sul, atualmente onde se concentram as maiores reservas de matéria-prima do planeta, estão em plena fase de desenvolvimento econômico.

Sendo ou não o Desenvolvimento Sustentável uma medida geopolítica de controle e domínio das lideranças econômicas sobre o desenvolvimento dos países emergentes; as mudanças climáticas, a poluição do ar e das águas são bastantes reais e sinalizam que é necessário frear e reavaliar o referencial de crescimento econômico e consequentemente as formas de utilização dos recursos naturais.

Deste modo, cabe avaliar o que é se desenvolver de forma sustentável, visando a absorção de pontos positivos desse paradigma para que a partir daí possam ser estabelecidos critérios e normas para estabelecer um desenvolvimento consciente, a fim de que as gerações futuras possam usufruir de um mundo melhor e mais equilibrado, onde o homem passe a entender-se como parte da natureza e que como tal precisa proteger-se para continuar existindo.

\section{Turismo Sustentável e Turismo em Áreas Naturais}

A Organização Mundial de Turismo - OMT define o turismo como "o conjunto de atividades que as pessoas realizam durante suas viagens e estadas em lugares distintos a seu entorno habitual por um período de tempo inferior a um ano, com fins de lazer, negócios e outros motivos não relacionados com o exercício de uma atividade remunerada no lugar visitado" (CUENTA, 2001 apud EMBRATUR, 2010, p. 75).

O conceito de Turismo Sustentável surge no contexto do Desenvolvimento Sustentável como alternativa para promover o crescimento econômico através de práticas turísticas que são desenvolvidas sobre as bases da sustentabilidade. Deste modo, Oliveira (2000, p. 34) define Turismo Sustentável, como o "turismo praticado de forma que promova a qualidade de vida das populações residentes na localidade de destino, respeite a sociodiversidade da comunidade receptora, por meio da conserva- 
A análise ambiental integrada norteando o planejamento Ecoturístico: uma proposta de estudo de caso em Duas Barras (RJ)

ção da herança cultural das populações e conserve os recursos naturais e paisagísticos deste local' (OLIVEIRA, 2000 apud GOES, 2007).

O Turismo em área natural é um ramo de atividade turística relativamente novo, no qual existe na literatura uma infinidade de conceitos que se misturam entre tipologia de turismo e atividades de turismo. Em vista de tal dificuldade, o MTUR (Ministério do Turismo), reunidos com membros representantes das ciências ambientais e interdisciplinares, desenvolveu um documento, que representa uma tentativa de direcionar e ordenar não só os vários aspectos do desenvolvimento desta prática turística, bem como definir conceitos (GOES, op. cit.).

Sendo assim, Turismo Sustentável em áreas naturais é o segmento do turismo que utiliza o patrimônio natural e cultural, de forma sustentável, com intercâmbio sob diferentes formas entre o homem e a natureza para promover a conservação dos recursos locais (físicos e humanos) aperfeiçoando os custos e ganhos ambientais, culturais, econômicos e sociais, orientado por planejamentos participativos (SETU, 2000). Para esta modalidade existe uma diversidade de tipologias, sendo as principais:

Ecoturismo e Turismo Ecológico: Conjunto de atividades turísticas, que utiliza de forma sustentável, os patrimônios naturais e culturais, incentivando a sua conservação e buscando a formação de uma consciência ambientalista, através da interpretação do ambiente, promovendo o bem-estar das populações envolvidas (EMBRATUR, 2010). A diferença entre Ecoturismo e Turismo Ecológico é que o primeiro é desenvolvido em Unidades de Conservação.

De acordo com MMA (2010), o Ecoturismo possui entre seus princípios a conservação ambiental aliada ao desenvolvimento das comunidades locais, devendo ser desenvolvidos sob os princípios da sustentabilidade com base em referencial teórico e prático e suporte legal. Ao contribuir com a conservação dos ecossistemas, o ecoturismo agrega ganhos para os interessados transitando tanto na esfera ambiental quanto na social e econômica fazendo-se cumprir as premissas de conservação, sustentabilidade e inclusão social. Mas, o verdadeiro desafio está em como incluir a sociedade de forma a inseri-la no processo de utilização racional dos recursos naturais das UCs, já que são nestes ambientes que devem ser praticadas, de forma sustentável, as atividades ecoturísticas. Outro desafio é saber como essa sociedade percebe o ambiente que o cerca, como aproveitar a sua cultura local nas atividades econômicas reais do ecoturismo, e, principalmente, motivá-las a deixar de lado outras práticas mais impactantes ao ambiente.

Turismo de Aventura: Segundo Ministério do Turismo (2010), Turismo de Aventura compreende os movimentos turísticos decorrentes da prática de atividades de aventura de caráter recreativo e não competitivo. Primeiramente foi entendido apenas como uma forma prazerosa de estar em contato com a natureza e sendo assim, foi associado como uma atividade do ecoturismo. Nos dias atuais esta prática turística, possui características estruturais e mercadológicas próprias associadas aos grupos nos quais as pessoas atuam como protagonistas, desenvolvendo atividades participa- 
tivas de menor ou maior intensidade.

Consideram-se movimentos turísticos, os deslocamentos e estadias que presumem as atividades desta tipologia. Outra observação que merece destaque refere-se a experiências físicas e sensoriais que envolvem liberdade, prazer, superação e desafios, mantendo ao mesmo tempo caráter recreativo, mas avaliando os riscos, controlados e assumidos, por parte do praticante.

Embora muitas vezes ainda confundido com ecoturismo, as atividades desta prática turística podem ocorrer em espaços naturais (sendo área protegida ou não), construídos, rural e urbano.

Para Costa et al. (2009), o que tem se desenvolvido é o Turismo na Natureza nas suas diferentes modalidades e não o Turismo Ecológico, visto que para este último, requer o controle das atividades de lazer e recreação que se desenvolvem muitas vezes em ambientes de níveis diferenciados de fragilidade ambiental, suscetíveis a movimento de massa e processos erosivos, impondo limitações às atividades e colocando o turista em situações de risco.

Ainda segundo os autores, ao falar em meio ambiente, nos referimos aos componentes físicos, ao clima e aos organismos vivos e neste caso, estes três grupos reunidos, formam o patrimônio natural e que se apresentam como recursos do turismo. Sendo assim, as características geológicas, geomorfológicas, climáticas, ou seja, a paisagem é a principal atração do turismo na natureza. Neste caso, a Geomorfologia tem contribuído significativamente no estudo das potencialidades e limitações das áreas de turismo da natureza, já que procura compreender os processos formadores dos relevos e a dinâmica externa que terão reflexo conforme o tipo de ocupação e neste caso inclui-se as atividades de visitação turística.

A Geomorfologia pode auxiliar no aproveitamento máximo das belezas naturais, visto que possibilita estudar uma diversidade de ambientes e desenvolve modelos que permitem diagnosticar e prever impacto nas diversas paisagens (COSTA et al., 2009).

\section{Visão Integrada (Geossistema)}

Tricard (1977), com seu conceito de Ecodinâmica, disseminou uma nova forma de ver a natureza e a sociedade através de uma abordagem integrada, sobretudo em questões da natureza sob os efeitos da sociedade. É importante destacar que o citado autor destaca que as intervenções humanas afetam primeiramente a cobertura vegetal, para desenvolver suas atividades, e tais ações vão repercutir sobre a radiação solar que alcança o solo, alterando a temperatura, sobre a fauna e a flora e fertilidade deste. Além disso, sob esse feito de ausência de cobertura vegetal, iniciam os processos erosivos devido ao enfraquecimento das estruturas do solo e sua baixa resistência a pluviosidade, regime hídrico e reciclagem dos elementos minerais (TRICARD, 1977 apud ROSS, 2009). 
A análise ambiental integrada norteando o planejamento Ecoturístico: uma proposta de estudo de caso em Duas Barras (RJ)

Em conformidade com ROSS (2009), é necessário se ter a compreensão do todo e, portanto, precisa analisar a natureza e a sociedade e suas dinâmicas para estabelecer diretrizes gerais e específicas do planejamento ambiental, seja este, regional, rural, urbano, sejam de todos estes simultaneamente. Sendo assim, é importante estabelecer um equilíbrio dinâmico de forma a privilegiar a conservação do meio ambiente, afim de não extinguir os recursos naturais.

No entanto, a perda de caráter natural ocorre principalmente, através da introdução imprópria (planejada ou acidental) de espécies exóticas. O impacto antrópico, causado por mau uso das áreas vegetadas, pode promover modificações ou levar à destruição desse ecossistema. Altos níveis de perturbações resultam em um decréscimo na altura e cobertura da vegetação, deixando o terreno exposto e vulnerável à ações erosivas. Ações ou uso impróprios podem resultar em problemas de administração sérios, para os quais soluções simples e baratas raramente estão disponíveis (ROSA, 2007 apud GOES, 2011).

Nesse contexto mundial de crescimento urbano acelerado, esta é uma preocupação constante que aquece a discussão entre preservação e conservação dentro de um paradigma de desenvolvimento sustentável que Ab'Saber (1994 apud ROSS, 2009, p. 55) discute com relação a importância da Geografia visto que esta ciência não deve ser separada em Geografia Física ou Geografia Humana, mas associada como a "Geografia da abordagem analítico-integradora e sintetizadora de uma geografia que se preocupa com o espaço total'.

O conceito de Geossistema na perspectiva Russa de Sotchava (1978 apud ROSS, 2009), propõe uma visão sistêmica que se apoia no planejamento e no desenvolvimento socioeconômico. Nesta abordagem a geografia não se detém apenas a estudar os aspectos físicos do ambiente, mas também as conexões entre elas. Para o autor, os Geossistemas abrangem os Ecossistemas, policêntricos, envolvendo a totalidade dos componentes naturais na perspectiva de suas conexões, inter-relações de dependência mútua e de seus aspectos funcionais (ROSS, 2009).

Para o francês Bertrand (1971 apud ROSS, op. cit.) o conceito de paisagem deve basear-se no conceito e nos métodos de Geossistema. Tendo como partida a teoria dos sistemas, ecólogos e biólogos definiram o conceito de Ecossistema de forma semelhante aos cientistas russos. Para este autor, "ecossistema não tem nem escala e nem suporte espaciais bem definidos" (p. 25). Unindo os conceitos de ecologia e geografia, surge o conceito de Geoecologia que se refere ao estuda da paisagem sob o ponto de vista ecológico.

Quanto a unidade de paisagem, considera todas as delimitações geográficas arbitrárias, sendo possível ir do micro ao macro, "vislumbrando uma taxonomia das paisagens com dominância física e com limites definidos". Para Bertrand (op. cit., p.27), "a unidade de paisagem é estabelecida em função da escala de tratamento das informações, podendo ser: zona, domínio, região, geossistema, geofácies e geótopos". 
Ao discutir o conceito de paisagem e suas implicações, torna-se imprescindível citar uma das atividades econômicas do setor terciário, porém já vista como setor secundário (indústria), que se encontra em plena ascensão no mercado e que tem a paisagem como matéria-prima, seja ela: o turismo. Pode-se dizer que a atividade turística consome a paisagem (MENDONÇA, 2001).

Turismo é um fenômeno econômico e social, que se estabelece pela necessidade das pessoas se deslocarem temporariamente para um determinado local com objetivo de lazer, descanso e recreação (IBGE, 2008). Embora já tenha registro da existência desta atividade desde a idade média, foi na era moderna que esta se consolidou como atividade econômica. Embalados pela necessidade do ócio, habitantes, em geral citadinos, se deslocam para ambientes que primam pela beleza cênica por motivos contemplativos, esportivos, culturais, etc.

Como atividade econômica que expõem e utiliza recursos naturais e humanos, faz-se aqui a necessidade de ser compreendida e estruturada, através de práticas de planejamento ambiental, principalmente gestão e educação ambiental, alicerçado sobre visão geossistêmica e sustentável. Quando não gerenciado de forma sustentável este tipo de atividade, ao invés de proporcionar desenvolvimento local, pode conduzir a impactos ambientais irreversíveis acarretando consequências sócio-econômicas e ambientais.

Desta forma, pode-se afirmar que atividades turísticas podem proporcionar impactos positivos e/ou negativos ao ambiente e a sociedade receptora (MENDONÇA, 2001). Neste viés, para ser considerado uma atividade sustentável deve transitar pelas dimensões do Desenvolvimento sustentável: social, econômica, ambiental e institucional, a fim de proporcionar bem estar social a população local e para as gerações futuras.

\section{Fragilidade Ambiental}

Dentro de uma visão integrada compreende-se o meio ambiente como um sistema ambiental na qual os componentes têm um arranjo próprio e estão conectados entre si. Nas palavras de Lieber (2000, p. 2):

\footnotetext{
Sistema é, portanto, uma forma lógica de apreensão da realidade... pode-se definir sistema como uma 'coleção de entidades' ou coisas, relacionadas ou conectadas de tal modo que 'formam uma unidade ou um todo', ou que 'propiciem a consecução de algum fim lógico a partir dessas interações conjuntas'. Cada componente se relaciona pelo menos com alguns outros, direta ou indiretamente, de modo mais ou menos estável, dentro de um determinado período de tempo, formando uma rede causal.
}

Para estudar a fragilidade ambiental devem-se considerar as ações antrópicas e equilíbrio dinâmico dos sistemas ambientais. $\mathrm{O}$ ambiente natural busca estar em 
A análise ambiental integrada norteando o planejamento Ecoturístico: uma proposta de estudo de caso em Duas Barras (RJ)

equilíbrio dinâmico em relação a troca de energia de entrada e saída do sistema. Ao sofrer algum tipo de intervenção deve-se observar a capacidade de resistência e de resiliência dos sistemas ambientais. Resistência é capacidade do sistema em permanecer inalterado face aos distúrbios externos e Resiliência, refere-se a capacidade do sistema retornar as suas condições originais após ser afetado por distúrbios externos (CHRISTOFOLETTI, 2009).

O homem através de ações ditas antrópicas se apropria do território causando grandes alterações na paisagem em ritmo muito mais intenso do que a natureza é capaz de suportar, alterando o fluxo energético dos sistemas ambientais e consequentemente provocando impactos no meio ambiente, quebrando o estado de equilíbrio dinâmico dos sistemas ambientes (SPÖL, 2001). Para exemplificar, podem ser citados os ciclos econômicos brasileiros e os intensos impactos ambientais que transformaram definitivamente a paisagem de biomas como no caso da Mata Atlântica, e mais recentemente do bioma Cerrado em processos agroindustriais.

Visando interesses econômicos, em geral, os estudos sobre as potencialidades são mais corriqueiramente encontrados e têm maior relevância do que estudos sobre fragilidade ambiental, visto que potencialidades expressam interesses em alguma forma de exploração dos recursos naturais existentes. Entretanto, os estudos sobre fragilidade ambiental são igualmente importante, principalmente quando se deseja saber a respeito da capacidade de suporte ou carga que um ambiente pode suportar (ROSS, 2009).

Para Spörl e Ross (2004), face as intervenções humanas, que condiz com mudanças tecnológicas, econômicas, sociais e ambientais, os sistemas ambientais podem apresentar maior ou menor fragilidade em função de suas características genéticas. Portanto, qualquer alteração nos diversos componentes da natureza como: relevo, clima, solo, vegetação e recursos hídricos, provocam desequilíbrios nas funcionalidades do sistema ambiental, quebrando o equilíbrio dinâmico. Para estes autores, neste caso, tratar estas variáveis de forma integrada e possibilita obter um diagnóstico das diferentes categorias hierárquicas das fragilidades dos ambientes naturais.

Para desenvolver a análise de sistemas, Spörl e Ross (op. cit.), propõem dois modelos de análise da fragilidade ambiental:

- Modelo de fragilidade potencial natural com apoio nos índices de dissecação do relevo, para este modelo consideram-se levantamentos: geomorfológicos, solos, cobertura vegetal, uso da terra e clima, na qual são analisados de forma integrada estabelecendo unidades de fragilidades dos ambientes. Para este primeiro considera-se que cada um desses temas seja hierarquizado de acordo com a sua vulnerabilidade. Sendo assim as variáveis mais estáveis apresentam valores mais próximos a 1 enquanto as mais vulneráveis se próxima de 5. Para este modelo o índice de dissecação do relevo é que vai determinar o grau de fragilidade do ambiente analisado enquanto a cobertura vegetal indicará a as áreas onde o ponto de equilíbrio foi rompido. 
- Modelo de fragilidade potencial natural com apoio nas classes de declividade: este segundo modelo é uma derivação do modelo anterior, onde ao invés de utilizar o tema dissecação de relevo, utiliza classes de declividade. A diferença entre o primeiro e o segundo modelo é que a identificação do grau de fragilidade da área de estudo torna-se muito fragmentada, tendo maior variabilidade em relação a identificação dos graus de fragilidade.

O modelo de CREPANI, através do Instituto nacional de Pesquisas Espaciais (INPE), foi desenvolvido para subsidiar o zoneamento ecológico econômico (ZEE) da Amazônia e visa determinar unidades territoriais básicas (unidades homogêneas de paisagem), elaborando mapas de vulnerabilidade natural a erosão. A estabilidade ou a vulnerabilidade ao processo natural a erosão é analisado com base nos temas de: solo, rocha, relevo, vegetação e clima. Nesta metodologia as variáveis têm o mesmo grau de importância não tendo peso diferenciando entre os temas. Portanto, cada unidade territorial básica recebe um valor que consiste na média aritmética dos valores individuais que quanto mais próximo a 1 são mais estáveis e quanto mais próximos ao 3 são vulneráveis.

Kawakubo et al. $(2005$, p.5) conceituam "fragilidade potencial a vulnerabilidade natural do ambiente e fragilidade ambiental a vulnerabilidade natural associada aos graus de proteção que os diferentes tipos de uso e cobertura vegetal exercem". Nessa proposta de modelo elabora-se um mapa síntese na qual utiliza cartas de declividade nas escalas grandes que vão de 1:2.000 a 1:25.000, padrão de relevo em escalas média a pequena, que vão de 1:50.000 a 1:250.000, além de cartas de solo e cobertura vegetal. As informações de geologia e clima são utilizadas como informações adicionais.

Os intervalos de declividade seguem os estudos de capacidade de uso/aptidão agrícola associados aos valores da geotecnia, que associados indicam o vigor dos processos erosivos, riscos de escorregamentos e inundações frequentes. Para padrão de formas, os valores de dissecação do relevo relacionam o plano horizontal enquanto a densidade de drenagem relaciona o plano vertical. A erodibilidade do solo está associada a vulnerabilidade do solo a erosão e o Uso do Solo que podem impactar positivamente ou negativamente.

O uso adequado evita perda de materiais enquanto a vegetação protege contra efeitos modificadores das formas de relevo. Para a viabilidade deste modelo utilizamse inúmeros produtos intermediários que viabilizam as análises até a geração do mapa síntese. Portanto o objetivo deste modelo é mapear a fragilidade ambiental utilizando técnicas de geoprocessamento.

COSTA et al. (2009), emprega o conceito de vulnerabilidade relacionada a fragilidade ambiental e cria o termo fragilidade ecoturística que significa a vulnerabilidade apresentada pela áreas turísticas a ocorrência de processos erosivos que podem causar riscos em decorrência de movimento de massa, associados ao uso do solo.

Em se tratando de turismo na natureza e a exposição de turista a ambientes 
A análise ambiental integrada norteando o planejamento Ecoturístico: uma proposta de estudo de caso em Duas Barras (RJ)

naturais é fundamental ter a compreensão do todo da área que está sendo utilizada para empreendimento turístico. Quando não analisadas sob o ponto de vista geossistêmico, este ambiente pode trazer situações de risco tanto para o turista como também problemas erosivos e de movimento de massa descaracterizando o ambiente e gerando danos ao local. Entretanto uma das finalidades de compreender o ambiente como um geossistema é a possibilidade de produzir estudo de capacidade de carga de áreas naturais que faz o reconhecimento das limitações impostas do ambiente, tornando fundamental a administração do fluxo de pessoas e de medidas mitigadoras na área visitada (ROCHA, 2007). Ainda de acordo com o autor, Capacidade de Carga Física (CCF) é o "limite máximo de visitas que se pode realizar em um determinado local durante o dia" (p. 3). Neste caso o estudo de capacidade de carga é um instrumento de gestão e planejamento ambiental importante a manutenção física do geossistema de áreas para visitação pública, principalmente aquelas voltadas ao ecoturismo.

\section{Geoprocessamento como ferramenta de análise}

Geoprocessamento enquanto ciência possui um aporte conceitual que vem sendo lapidado a cada geração. Dentre os autores mais relevantes vale citar Burrough e Mc Donnel (1998, apud ROCHA, 2000) que definem:

\footnotetext{
Geoprocessamento é o conjunto de ferramentas usadas para coleta e tratamento de informações espaciais que armazena as informações geográficas em formato digital gerando saídas em forma de mapas e relatórios e que permitem a manipulação de dados para geração de novas informações (p. 47-48).
}

O termo Geoprocessamento denota a disciplina do conhecimento que utiliza técnicas matemáticas e computacionais para o tratamento da informação geográfica e que vem influenciando de maneira crescente as áreas de Cartografia, Análise de Recursos Naturais, Transportes, Comunicações, Energia e Planejamento Urbano e Regional. As ferramentas computacionais para o Geoprocessamento, chamadas de Sistemas de Informação Geográfica (GIS), permitem realizar análises complexas, ao integrar dados de diversas fontes e ao criar bancos de dados georreferenciados (CASANOVA, et al, 2005).

O Instituto de Pesquisas Espaciais (INPE) traz um viés da teoria dos sistemas assentado sobre a Geomática, onde define Geoprocessamento como conjunto de tecnologias que utilizam representações computacionais do espaço para modelar e analisar fenômenos espaço-temporais (CAMARA, 2004).

O termo Geomática nasceu originariamente no Canadá, onde essa ciência foi desenvolvida para descrever o campo de tecnologias relacionadas à informática e comunicação de dados. Os objetos de estudo da Geomática passam pela captura, armazenagem, análise, apresentação, distribuição e gerenciamento de informações es- 
paciais com vistas à tomada de decisões nos campos científico, administrativo, legal e operacional. A intensa valorização das Geotecnologias proporcionou o impulso necessário para o desenvolvimento de uma ciência específica, voltada para o estudo dessas tecnologias vinculadas à Geoinformação (CAMARA, 2004).

Desde a automação da cartografia e a popularização dos PC's, nos anos 80 , cada vez mais as ferramentas de geoprocessamento vem fazendo parte do cotidiano de profissionais das geociências, unindo uma coleção de planos de informação vetorial e matricial em um mesmo ambiente, produzindo mapas temáticos, associado a banco de dados relacional e minimizando o tempo de processamento, esta ferramenta veio a corroborar com a visão integrada através da espacialização da informação.

Segundo Santos (2009) um caminho para representar a integração de dados ambientais é por meio da discretização, segmentação e estratificação do espaço em unidades territoriais homogêneas. Agrupando todos os temas envolvidos na análise, torna-se possível observar as características de cada ponto do território. Neste caso, a análise espacial, pode ser viabilizada através de material ou via banco de dados geográficos utilizando Sistemas de Informações Geográficas (SIG).

Outro ponto interessante que pode ser bastante explorado nos SIG's são as técnicas de análise multi-critério, que possibilita avaliar as modificações de uma porção do espaço durante um intervalo de tempo, e a elaboração de indicadores, que além das características já citadas, permitem também representar a rede de causalidades presentes em um determinado meio, através de análise comparativa e avaliação entre territórios de diferentes dimensões e complexidades.

Diante de tais característica pode-se constatar que os SIG's são excelentes aliados tanto como ferramenta de análise, dentro de uma visão integrada do meio ambiente, como também como ferramenta de gestão para tomada de decisão, haja visto a sua capacidade de simular situações presentes e futuras no espaço observado. Sendo assim, os SIG's ocupam papel relevante nas etapas do planejamento ambiental.

Ainda de acordo com Santos (2009, p. 54), "um mapa não é uma simples representação espacial da informação", já que para produzi-lo é necessário passar por processo de construção do conhecimento. Portanto vinculado ao mapa é necessário uma visão crítica e analítica do que está sendo representado.

\section{A relação com a proposta de pesquisa}

A área de estudo localiza-se no município de Duas Barras que está situado na Região Serrana do Estado do Rio de Janeiro. Esta área insere-se na faixa de alinhamento de cristas do Paraíba do Sul, tendo somente a porção sul do território no contexto de escarpas e reversão da Serra do Mar, apresentando em seu território as serras: do Borrão ao Norte, do Garrafão a Nordeste, do Pontão a Sudeste, Bento Santo ao sul, do Monte Verde a Noroeste e do Paquequer (GOES, 2007). 
A análise ambiental integrada norteando o planejamento Ecoturístico: uma proposta de estudo de caso em Duas Barras (RJ)

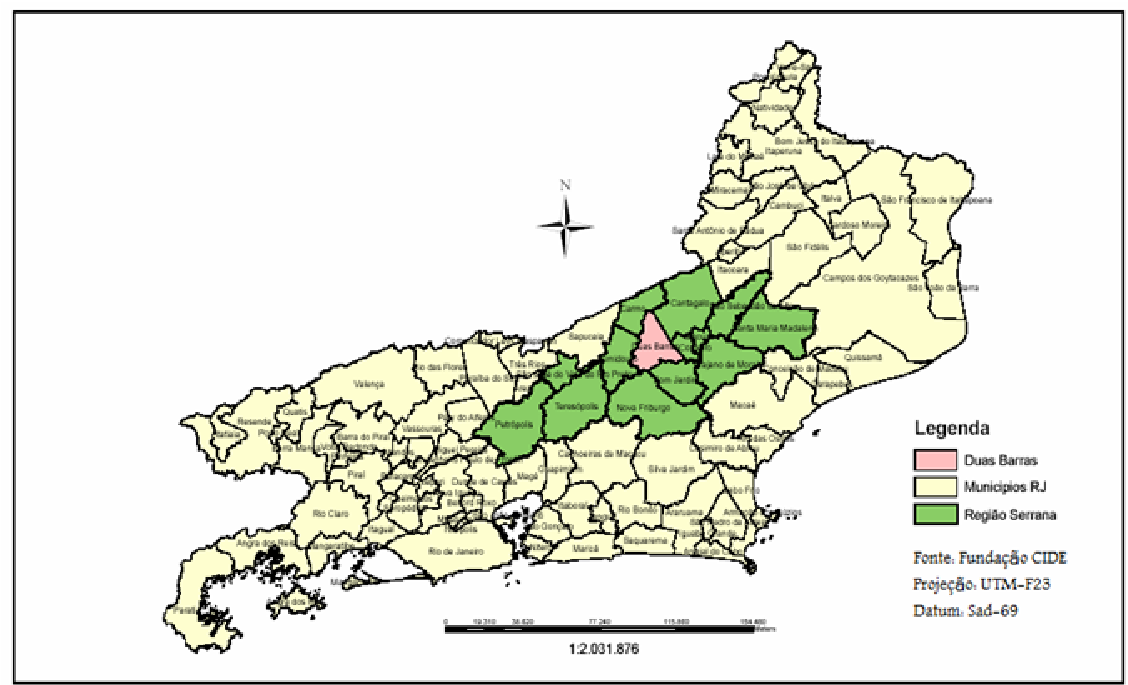

Figura 1: Localização da Área de Estudo. Fonte: LabGeo (CIDE, 2007). Figure 1: Location of the Study Area. Source: LabGeo (CIDE, 2007).

Quanto às unidades de paisagem, ao norte encontram-se formações que englobam relevos de dissecação estrutural orientados, constituindo cristas assimétricas e escarpas que coalescem com rampas de colúvio ou "mares de morros" e colinas convexas; ao sul abrange modelados estruturais representados por cristas de topos aguçados, pães -de-açúcar, morros, pontões, escarpas, com incisões de drenagem e ao centro encontram -se relevos colinosos, com vertentes convexas e topos convexizados ou tabulares, intercalados por alvéolos, com incisões de drenagem (MME, 1983 apud GOES, 2007)

As altitudes variam entre 550 a $1000 \mathrm{~m}$ e a sede municipal fica instalada a $530 \mathrm{~m}$ de altitude. Com relação à cobertura vegetal, grande parte da região é composta por pastagens $(35,7 \%)$ e vegetação secundária $(37,25 \%)$, tendo também presença de Floresta Montana (TCRJ, 2005 apud GOES, op. cit.).

Em zoneamento turístico realizado por GOES (2007), utilizou técnicas de SIG aliada a análises multi-critérios para identificar quais as vocações turísticas para este território. Como resultado concluiu-se que Duas Barras possui vocação para turismo de aventura, turismo histórico-cultural, turismo rural e turismo ecológico. Para esta pesquisa considerou-se dados socioeconômicos e dados de declividade e uso do solo para determinar as áreas propícias em desenvolvimento deste tipo de empreendimento turístico. Como unidade de análise considerou-se os setores censitários.

Em um segundo momento, foi construído por GOES (2011), um novo mapa de uso do solo usando técnicas de Processamento Digital de Imagem tendo como insumo imagens do tipo LANDSAT 5 TM (2010, bandas 5, 4, 3). Nesta pesquisa, detectou que em aproximadamente 9 anos o Município de Duas Barras teve perdas de cerca de $20 \%$ de sua cobertura vegetal em detrimento do avanço de atividades agropecuárias (café, pecuária de leite e plantio de eucalipto). Apesar de ser uma região bastante íngreme, em visitas técnicas realizadas no local, observou-se que não estão sendo utilizadas técnicas de plantio em terraços e que as áreas de pasto e o sopé dos maciços estão invadidos por 
plantação de eucalipto. Outra observação importante foi detecção de plantação de lavoura de subsistência e áreas de declividade elevada e um solo raso.

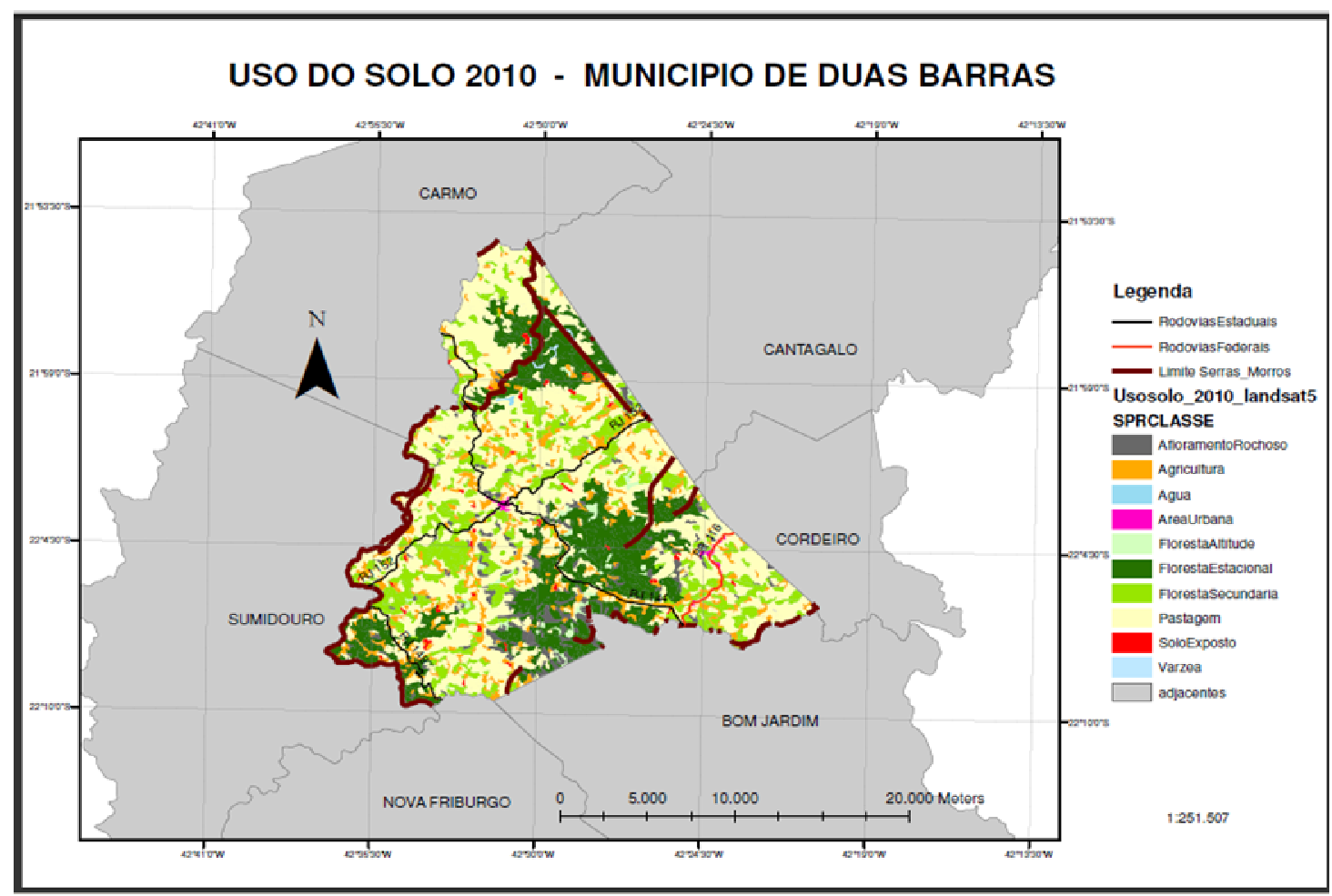

Figura 2: Uso e ocupação do Solo 2011. Fonte: GOES (2011).

Figure 2: Land Use and occupation in 2011. Source GOES (2011).

\section{Considerações finais}

Diante deste cenário, composto por pesquisas anteriores, nesta nova etapa, a ser implementada como projeto de dissertação de mestrado, serão realizados mapeamentos sobre as fragilidades e potencialidades do município de Duas Barras, tendo como unidade de análise as bacias e sub-bacias hidrográficas da região, acrescentando dados sociais e do setor produtivo de forma a possibilitar uma visão integrada do território.

Em um viés geossitêmico, o objetivo deste diagnóstico será o de desenvolver um instrumento que possa subsidiar não somente o planejamento ecoturístico, instalando empreendimentos turísticos que minimizem os riscos e produzam menos impactos negativos no ambiente e que ponham em risco o poder de resiliência de locais cuja fragilidade ambiental seja alta. Assim, será considerado como instrumento de tomada de decisão, no que concerne a gestão ambiental, o uso de SIG. A análise integrada com a visão geográfica da fragilidade ambiental, associada às ferramentas de geoprocessamento, subsidiará a pesquisa pretendida.

Além de uma coletânea de mapas específicos de geologia, geomorfologia, pedologia, hipsometria, declividade, fragilidade ambiental, pontos turísticos, perfil social (renda, 
A análise ambiental integrada norteando o planejamento Ecoturístico: uma proposta de estudo de caso em Duas Barras (RJ)

instrução, saneamento, faixa etária, densidade demográfica) e setores produtivos, um dos principais produtos desta pesquisa é a espacialização dos geoindicadores que sintetizam as áreas de fragilidade e vulnerabilidade ecoturística do município de Duas Barras.

Por se tratar de uma pesquisa na área de Turismo Sustentável, será necessário atualizar informações da dimensão socioeconômica e para tal pretende-se também atualizar os dados do censo demográfico 2010 para água, esgoto e lixo, atualizando o indicador de saneamento, renda, instrução e a criação de um novo índice que caracterize o perfil da população local quanto a faixa etária. No primeiro trabalho (2007), visando identificar a vocação, foram criados índices ressaltando a situação ótima de cada setor censitário. Nesta nova fase, os índices deverão ser recalculados e revisados favorecendo situações de criticidade. Tal decisão favorece estudos sobre a vulnerabilidade, identificando ameaças sociais e econômicas e, por último, serão geradas informações sobre a região que subsidiarão estudos mais detalhados sobre a inserção social que é um dos objetivos do turismo sustentável (ecoturismo).

A partir de documentação gerada com o diagnóstico, munidos de informações acerca do território em estudo, é possível desenvolver planos de manejo, criar programas ambientais que mitiguem os impactos acarretados pela atividade (Eco) Turística e outros que promovam a inserção social. O prévio conhecimento da área fornece o subsídio necessário para o desenvolvimento da atividade econômica com impactos menores, se adequando as dimensões do desenvolvimento sustentável.

\section{Referências bibliográficas}

CÂMARA, G.; MONTEIRO, A. M.; MEDEIROS, J.S.M.. Introdução a Ciência da Geoinformação.São José dos Campos, INPE, 2004. Disponível em: <http://www.dpi.inpe.br/ livros.php>. Acesso em: 20 de out. 2010.

CASANOVA. M; CAMARA, G,; DAVIS, C, L.; VINHAS, Q. M. (ed). Banco de dados Geográficos. Curitiba, Editora MundoGEO, 2005. Disponível em: <http://www.dpi.inpe.br/ livros/bdados/>. Acesso em: 15 jun. 2010.

COSTA, N.C.; COSTA, V.C.; CONCEIÇÃO, R.S.; RIBEIRO, J.V.M. Fragilidades Turisticas em Áreas de Atrativos no Parque estadual da Perdra Branca. Geo UERJ, Ano 11, v.2, n.19, 1ํ semestre de 2009, pp. 138-160. Rio de Janeiro. 2009.

CHRISTOFOLETTI, A. Modelagem de Sistemas Ambientais. São Paulo: editora Edgard Blucher. 1999. p 159.

DELAMARO, M.C.; SAVIOLO, S.; SANTOS, J.H.O.; BURSZTYN, I.; DELAMARO, L.S.L.; OLIVEIRA, E.D'; MUDADO, T. Turismo nas Fazendas Históricas do Vale do Paraíba Fluminense: Um estudo sobre sustentabilidade. 2002. Disponível em $<$ http:// www.ivt.coppe.ufri.br/caderno/ojs/include/>. Acessado em 02/12/06.

EMBRATUR. Empresa Brasileira de Turismo. Turismo Marcos Conceituais. Secretaria Nacional de Políticas de Turismo Departamento de Estruturação, Articulação e Ordenamento Turístico. 2010. Disponível em: <http://www.turismo.gov.br/export/sites/default/ turismo/o ministerio/publicacoes/downloads publicacoes/ Turismo de Aventura Versxo Final IMPRESSxO .pdf>. Acessado em: 19/07/2011. 
EMBRATUR. Empresa Brasileira de Turismo. . Ecoturismo: orientações básicas. / Ministério do Turismo, Secretaria Nacional de Políticas de Turismo, Departamento de Estruturação, Articulação e Ordenamento Turístico, Coordenação Geral de Segmentação. 2. ed.

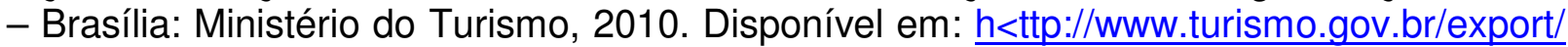
sites/default/turismo/o ministerio/publicacoes/downloads publicacoes/

Livro Ecoturismo.pdf> Acessado em: 19/07/2011.

GOES, K.R. Análise da Vocação Turística: O caso do Municipio de Duas Barras - RJ. Trabalho de conclusão do curso de Análise Ambiental e Gestão do Território. ENCEEscola Nacional de Ciências Estatísticas, 133 p. 2007.

GOES, K.R. Monitoramento do Uso do Solo de Duas Barras (RJ), usando Técnicas de Processamento Digital de Imagens por Sensoriamento Remoto. Trabalho de Conclusão de Curso em Bacharel em Geografia. Universidade Gama Filho, 78 p. 2011.

IBGE. Instituto Brasileiro de Geografia e Estatística. Economia do Turismo uma perspectiva macroeconômica - 2000-2005. Ministério do Planejamento, orçamento e Gestão. Vol.7. 2008.

KAWAKUBO, F.S.; MORATO, R.G.; CAMPOS, K.C.; ROSS, J.L.S. Caracterização Empírica da Fragilidade Ambiental Utilizando Geoprocessamento. Anais XII Simpósio de Sensoriamento Remoto. Goianla, 2006.p 2203-2210. Disponível em: <http://marte.dpi.inpe.br/ col/ltid.inpe.br/sbsr/2004/11.19.16.10/doc/2203.pdf>. Acessado em 19/07/2011.

LIEBER. R.R. Teoria dos Sistemas. UNESP- São Paulo, ed. Hemus, s/d. p.p11229.2000. Disponível em: <http://www.google.com.br/search?

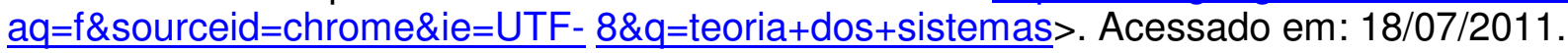

MENDONÇA, R. Turismo ou meio-ambiente: uma falsa oposição. In: LEMOS,

A.I.G. (org). Turismo: Impactos Socioambientais. São Paulo: Editora Hucitec, p.19-25, 2001

MMA - Ministério do Meio Ambiente. Declaração de Jonesburgo Sobre Desenvolvimento Sustentável. <www.mma.gov.br/estruturas/ai/ arquivos/decpol.doc $>$. Acessado em 27/11/07.

OLIVEIRA, L.A. Mapeamento Semântico do Turismo Sustentável. 2000. Disponível em $<$ http://www.senac. br/informativo/bts/301/boltec301b.htm>. Acessado em 31/08/2006.

ROCHA, C.H.B. Análise Ambiental da Capacidade de Carga nas Trilhas dos Circuitos das Águas e Pico do Peão - Parque Estadual de Ibitipoca - MG. Anais II ECOUC-Encontro Interdisciplinar de Ecoturismo em Unidades de Conservação. Itatiaia. Rio de Janeiro, 2007. Disponível em: <http://www.physis.org.br/ecouc/Artigos/Artigo4.pdf>. Acessado em: 20/07/2011.

ROCHA, C.H.B. Geoprocessamento Tecnologia Transdisciplinar. 2000.

ROSS, J. Ecogeografia do Brasil: Subsídios para o planejamento ambiental. Oficina de textos. São Paulo, 2009. 
A análise ambiental integrada norteando o planejamento Ecoturístico: uma proposta de estudo de caso em Duas Barras (RJ)

SETU - Secretaria de Estado de Turismo do Paraná. Diretrizes para o turismo em áreas naturais no Estado do Paraná. Curitiba. Dez.2000.

SANTOS, R.F.. Planejamento Ambiental: teoria e pratica. Oficina de Textos. São Paulo, 2004

SPÖRL, C.; ROSS, J.L.S. Análise Comparativa da Fragilidade Ambiental com Aplica-

ção de Três Modelos. GEOUSP - Espaço e Tempo, São Paulo, no 15, PP 39-49, 2004.

Disponível em: <http://marte.dpi.inpe.br/col/dpi.inpe.br/sbsr@80/2006/11.13.15.54/ doc/3311-3318.pdf>. Acessado em: 12/07/2011.

\begin{abstract}
Notas
${ }^{1}$ Relatório Nosso Futuro Comum ou Relatório Brundtland foi publicado em 1987, no qual desenvolvimento sustentável é concebido como "o desenvolvimento que satisfaz as necessidades presentes, sem comprometer a capacidade das gerações futuras de suprir suas próprias necessidades.

${ }^{2}$ Clube de Roma é um grupo de líderes da academia, indústria, diplomacia e sociedade civil se reuniu num pequeno vilarejo em Roma, Itália. Sua preocupação era identificar os maiores problemas perante o globo, e o grupo desenvolveu um conceito chamado World Problematique.

${ }^{3}$ Agenda 21 é um programa de ação para viabilizar a adoção do desenvolvimento sustentável e ambientalmente racional em todos os países (MRE, 2007).
\end{abstract}

Kátia Regina Góes-Souza: Universidade do Estado do Rio de Janeiro, Rio de Janeiro, Brasil.

Email: katia.goes@gmail.com

Link para o currículo Lattes: http://lattes.cnpq.br/3487375169780084

Vivian Castilho da Costa : Universidade do Estado do Rio de Janeiro, Rio de Janeiro, Brasil.

Email: vivianuerj@gmail.com

Link para o currículo Lattes: http://lattes.cnpq.br/3181407490194397

Data de submissão: 08 de março de 2012

Data de recebimento de correções: 12 de março de 2012

Data do aceite: 12 de março de 2012

Avaliado anonimamente 